\title{
Exploring Parental Perception: What Is Keeping Indian Children with Intellectual and Developmental Disabilities out of Schools?
}

\author{
Rakshita Shekhar \\ University of Kent, $U K$
}

\begin{abstract}
Children with intellectual and developmental disabilities (CWIDD) continue to be the most vulnerable to educational exclusion in India. To explore, in detail, the perceptions, experiences, beliefs, expectations, desires and needs of parents, regarding the education of their CWIDD, and in turn, identify barriers to the school going behavior of CWIDD, semi structured interviews of 30 parents of 32 CWIDD were analyzed using thematic analysis. Findings suggest that parents believe education is necessary but that mainstream schools don't care for their child. Although they also believed that special schools understood and helped their child, data indicated that most children who ever attended special schools had dropped out. Lack of basic carelempathy and necessary adaptations as well as expulsion, were cited as reasons for pull-out from mainstream schools. Drop out from special schools was triggered by child's disinterest and lack of transport. This study has found preliminary evidence that Indian parents want their CWIDD to be educated and prefer mainstream schools over special schools. In addition, negligence, discrimination and lack of supportive learning environments at school, prompt them to keep their children out of schools. Thus, this study lends further support to a fully inclusive school system. Suggestions are made to ensure that the educational rights of CWIDD are upheld.
\end{abstract}

\section{Introduction}

629000 children in India have IDD. $41 \%$ of those between ages 5 and 19 have never attended school. In comparison, $18 \%$ of visually impaired, $21 \%$ of hearing impaired and $23.72 \%$ of children with orthopedic disabilities have never attended school [1]. Between 2000 and 2014, 35.97\% of CWIDD were out of school. But $2.97 \%$ non-disabled children, including $4.2 \%$ belonging to scheduled tribes and $3.24 \%$ belonging to scheduled castes, groups identified as the most vulnerable to educational exclusion in India, were out of school [2].

These numbers clearly indicate that children with intellectual and developmental disabilities (CWIDD) are at the highest risk of being excluded from schools. However, there is lack of literature identifying factors that prevent their access to education.

Peshawaria et al [3] reported that lack of school transport was a hindrance. Parents in Kalita and Sarmah's study [4] cited frustration as the most common reason for pulling their disabled child out of school. A more recent governmental survey [2] reported disability and health of the child as the reasons. Interestingly, this same survey also found that poverty was the most common barrier in the entire study, but did not specify how common this theme was among CWIDD.

The limitation of these studies was that they were not focused on understanding barriers to school access. Multiple studies have been undertaken on inclusive education by the government of India [5]. But these studies have been conducted on the entire cohort of children identified as having special educational needs, due to which the unique educational needs of CWIDD have become invisible. Some studies do present data on CWIDD [1,2]. But these have used non-standard and thus, unreliable methods to identify CWIDD.

Hence, there is a need to conduct a study focused on CWIDD, to find out why so many of them are out of school. One important way to do this is to consider parents' perspectives because they are the primary decision makers in children's lives.

One of the first studies exploring educational perceptions of Indian parents having children with disabilities was conducted in 1995 [3]. Participants in this study expressed worry for their child's future due to low academic achievement. Researchers in this study went on to develop the NIMH family needs schedule but it had only 3 basic questions on educational needs: do you need transport; do you need help deciding on a service; do you need information on the effect of sending your child to either a mainstream school or a special school.

More recent research shows that Indian parents use religious, biological and situational factors to understand disability $[6,7]$. They see education as an access to independence of their child [8]. They move from regular educational settings to special educational ones [7]. However, the objective of these recent studies was to understand the perception of IDD that parents held and their consequential coping models. 
Therefore, the current study was designed to explore in detail, the perceptions, experiences and beliefs that parents held about the education of their CWIDD and the motivations for their decisions around education, with an objective to identify barriers to school going behavior of CWIDD and understand expectations, desires and needs of these parents, which if met, could improve this behavior.

\section{Method}

Purposive sampling and snowballing were employed to recruit parents of children, of Indian origin, between the ages of 6 and 18, living in India and diagnosed with IDD. 36 parents (representing 38 children) participated in this study. 6 participants hailed from the city of Bangalore and the rest, from Hyderabad.

They were interviewed for 45-60 minutes using semi structured interviews. While 1 participant revealed during the interview that their child was over the age of 18,1 withdrew from the study. 4 participants did not provide complete information and therefore were excluded from analysis. In the final sample, 5 children were going to a mainstream school, 7 to a special school, 11 had dropped out and 9 had either never attended school or attended school for a total of less than 6 months (This group will hence be called "no school", for convenience). An active attempt was made not to recruit more than 2 participants from the same school, to avoid sampling bias.

The final sample consisted of a total of 26 mothers and 4 fathers. 2 groups of siblings are represented in the sample. For the first group, both parents gave interviews and therefore, they have been accounted for, as 2 different participants (P13, P14). In the other case, only the mother was available for an interview. Therefore, her children have been assigned serial numbers 11.1, 11.2 and 11.3.

Ethics approval was received for this study from the Tizard Centre Ethics Committee, University of Kent, UK.

19 interviews were conducted at homes of the participants and 11 at the child's school. Only as much detail as was directly relevant to the study, was asked for. All parents voluntarily showed their child's disability card and shared information about co-morbid issues.

The researcher realized that differences in socioeconomic statuses between them and the participants created a power imbalance, which could lead to acquiescence and false consent. Therefore, no direct contact was made by the researcher prior to receiving consent of participation. A mediator already known to the participant would initiate contact. If interest in participation was expressed, an interview would be set up. If the venue was to be the participant's home, the mediator would lead the researcher to the venue. A total of 9 mediators helped: 4 of them were special educators, 1 was a personal acquaintance of the researcher and 1 was a home-based-education teacher from the National Institute for the Empowerment of Persons with Intellectual Disabilities (NIEPID). Interestingly, 3 participants voluntarily enrolled 8 of their friends into this study. Phone numbers and/or addresses were recorded only if the participant requested for further communication/help regarding their CWIDD.

Most of the participants neither possessed an email ID nor knew how to operate a computer. Due to this, the information packet could not be sent before the meeting. Participants who were fluent in English were given about 15 minutes to read through the information packet. Their understanding was confirmed on the essential sections of the forms in a sensitive manner. However, most participants did not speak, read or write English. Since the cost of professional translation threatened to exceed the budget allocated for this project, the mediator was asked to translate the content of the forms and explain both pros and cons of consenting. Although the researcher was fluent in those languages, she did not carry out this task to avoid acquiescence. If the mediator could not be present during the interview, a family member was called in. In case no family member fluent in reading and comprehending English was present, the participant was encouraged to call a trusted neighbor. They were given as much time as they needed to decide. The signed consent form was retrieved only after the parent expressed satisfaction with the contents of the forms.

Thematic analysis was applied to the data. After the interviews were transcribed, the transcripts were coded line by line. They were read multiple times so that the researcher could immerse herself in the data. These were then grouped into bigger themes and interesting, relevant quotes were noted down. The bigger themes with their relevant codes were penned down on flash cards. Then, all the flash cards having the same theme were grouped and read again. Common sub themes were identified and entered in a Microsoft excel for each participant. These sub themes were then regrouped into 4 major themes and some sub themes. Inevitably, some themes were omitted so that only the main points came across. The coding process was primarily completed by one researcher. This is an acceptable practice as per Braun and Clarke $[9,10]$. It is based on the premise that thematic analysis does not produce "a real" picture. Rather, it is an active, reflexive, and creative process undertaken by the researcher.

Themes and their names underwent multiple reiterations. The author's dissertation supervisor guided this process. 


\section{Reflexivity}

This section has been written in the first person as per recommendation in [10].

During this study, I interacted with the participants on 2 occasions: first, during the interview and the second time during the analysis phase.

During the interview, I would begin with the question, "when did you know that there is something atypical about your child?" This question was chosen because it was probably the beginning of their journey with IDD too. I would try to actively listen and observe their body language, try not to look away so that they knew that I was interested in what they were saying. When they cried, I kept a serious face. I would try to let them be so that they knew it was ok. But there were times, although rare, when I drifted. Sometimes, the disabled child would try to come and play with me. I would choose to take that opportunity to play. Perhaps, this influenced what the participant was saying or not saying to me. However, no participant expressed dislike for my behavior. On the contrary, all of them thanked me genuinely for listening to them.

I would always come back and write a diary note about the participant. Some days, I came back feeling angry that I couldn't help them immediately. Those days, my diary notes perhaps had interpretations that the participants themselves did not convey. Perhaps, the questions I had asked them during the interview, after the point I started feeling helpless, were also influenced by this emotion.

During the transcription phase, my emotions fluctuated and I got bored sometimes. But I would return and redo those sections.

In the analysis stage, there was a conscious effort to find words to fit in with what I was feeling or thinking because I assumed that the participants would have felt the same or thought on the same lines too. My supervisor helped me here, to become neutral, to look more objectively, to highlight my false assumptions or present sides that I hadn't considered before.

The results also reflect what I think is important in the data corpus present with me. It can be possible that a replication by another researcher may bring out some new results that I had not paid attention to.

Therefore, in this study, I do not claim that the results are the absolute truth. But it is very likely that these results portray a picture that is worth considering more deeply, so that the educational rights of the children represented in this study are upheld.

\section{Results}

The demographic details of participants and their children are given in Table 1 and Table 2.
Most participants' children either had moderate or severe ID and some were Autistic. Challenging behavior and epilepsy were present in 3 children each, active drooling in 4, and sleeplessness in 1.12 children had mobility issues. Thus, less than onethird of the sample of children had no co-morbid issues. No information is available on whether any of the children had undergone a genetic assessment to determine the cause of disability.

Table 1. Demographic details

\begin{tabular}{|c|c|c|c|}
\hline Code & $\begin{array}{l}\text { Interviewed } \\
\text { parent }\end{array}$ & $\begin{array}{l}\text { Child } \\
\text { Gender }\end{array}$ & $\begin{array}{c}\text { Child Age } \\
\text { (years) }\end{array}$ \\
\hline $\mathrm{P} 1$ & Mother & Male & 11 \\
\hline $\mathrm{P} 2$ & Mother & Male & 11 \\
\hline P3 & Mother & Male & 7 \\
\hline P4 & Father & Female & 18 \\
\hline P5 & Mother & Female & 14 \\
\hline P6 & Mother & Male & 17 \\
\hline P7 & Mother & Female & 10 \\
\hline P8 & Mother & Male & 18 \\
\hline P9 & Mother & Female & 16 \\
\hline P10 & Mother & Female & 14 \\
\hline P11.1 & Mother & Male & 16 \\
\hline P11.2 & Mother & Male & 14 \\
\hline P11.3 & Mother & Female & 13 \\
\hline P13 & Mother & Male & 14 \\
\hline P14 & Father & Male & 13 \\
\hline P15 & Mother & Male & 11 \\
\hline P16 & Father & Male & 10 \\
\hline P18 & Mother & Female & 18 \\
\hline $\mathrm{P} 20$ & Mother & Female & 9 \\
\hline $\mathrm{P} 21$ & Mother & Female & 15 \\
\hline P22 & Mother & Male & 6 \\
\hline $\mathrm{P} 23$ & Father & Female & 10 \\
\hline $\mathrm{P} 24$ & Mother & Female & 6 \\
\hline $\mathrm{P} 25$ & Mother & Male & 10 \\
\hline P27 & Mother & Male & 16 \\
\hline $\mathrm{P} 28$ & Mother & Female & 9 \\
\hline P29 & Mother & Female & 13 \\
\hline $\mathrm{P} 30$ & Mother & Male & 16 \\
\hline $\mathrm{P} 31$ & Mother & Male & 13 \\
\hline P32 & Mother & Female & 14 \\
\hline P33 & Mother & Male & 13 \\
\hline P34 & Mother & Male & 13 \\
\hline
\end{tabular}

Slightly more boys were present in the sample than girls. The average age of the entire sample was 
12.8 years. One third of the children were aged between 13 and 14 and a similar number fell in the age group of 15-18 years. The average age of children currently in mainstream schools was 10 years; of those in special schools was 12.1 years; of those in the no school category was 12.2 years and of drop outs, was 14.8 years.

Table 2. More demographic details

\begin{tabular}{|c|c|c|c|}
\hline Code & School Status & $\begin{array}{l}\text { Economic } \\
\text { Category }\end{array}$ & $\begin{array}{c}\text { Comorbid } \\
\text { Issue }\end{array}$ \\
\hline $\mathrm{P} 1$ & $\begin{array}{l}\text { Mainstream } \\
\text { School }\end{array}$ & FBP & None \\
\hline $\mathrm{P} 2$ & $\begin{array}{l}\text { Mainstream } \\
\text { School }\end{array}$ & FBP & None \\
\hline P3 & $\begin{array}{l}\text { Special } \\
\text { School }\end{array}$ & FBP & None \\
\hline $\mathrm{P} 4$ & Dropped out & FUP & Epilepsy \\
\hline P5 & Dropped out & FUP & $\begin{array}{l}\text { Mobility } \\
\text { Issues }\end{array}$ \\
\hline P6 & Dropped out & FUP & $\mathrm{CB}$ \\
\hline P7 & Dropped out & FUP & $\begin{array}{l}\text { Mobility } \\
\text { Issues }\end{array}$ \\
\hline $\mathrm{P} 8$ & Dropped out & FUP & None \\
\hline P9 & Dropped out & FUP & Drooling \\
\hline P10 & $\begin{array}{l}\text { Special } \\
\text { School }\end{array}$ & FUP & Drooling \\
\hline P11.1 & $\begin{array}{l}\text { Special } \\
\text { School }\end{array}$ & FUP & Drooling \\
\hline P11.2 & $\begin{array}{l}\text { Special } \\
\text { School }\end{array}$ & $\begin{array}{c}\text { Same as } \\
\text { above }\end{array}$ & none \\
\hline P11.3 & $\begin{array}{l}\text { Special } \\
\text { School }\end{array}$ & $\begin{array}{c}\text { Same as } \\
11.1\end{array}$ & $\begin{array}{c}\text { Drooling } \\
\text { and mobility } \\
\text { issues }\end{array}$ \\
\hline P13 & No School & FBP & $\begin{array}{l}\text { Mobility } \\
\text { Issues }\end{array}$ \\
\hline P14 & No School & FBP & $\begin{array}{c}\text { Mobility } \\
\text { Issues }\end{array}$ \\
\hline P15 & $\begin{array}{l}\text { Special } \\
\text { School }\end{array}$ & FUP & $\mathrm{CB}$ \\
\hline P16 & $\begin{array}{l}\text { Special } \\
\text { School }\end{array}$ & FBP & None \\
\hline $\mathrm{P} 18$ & Dropped out & FUP & None \\
\hline $\mathrm{P} 20$ & $\begin{array}{l}\text { Mainstream } \\
\text { School }\end{array}$ & FUP & $\begin{array}{l}\text { Mobility } \\
\text { Issues }\end{array}$ \\
\hline $\mathrm{P} 21$ & No School & FUP & $\begin{array}{l}\text { Mobility } \\
\text { Issues }\end{array}$ \\
\hline $\mathrm{P} 22$ & No School & FUP & Epilepsy \\
\hline $\mathrm{P} 23$ & Dropped out & FUP & None \\
\hline $\mathrm{P} 24$ & $\begin{array}{c}\text { Mainstream } \\
\text { School }\end{array}$ & FBP & None \\
\hline $\mathrm{P} 25$ & No School & FUP & $\begin{array}{c}\text { Mobility } \\
\text { Issues }\end{array}$ \\
\hline $\mathrm{P} 27$ & No School & FUP & $\begin{array}{l}\text { Mobility } \\
\text { Issues }\end{array}$ \\
\hline P28 & No School & FUP & $\begin{array}{c}\text { Sleepless- } \\
\text { ness }\end{array}$ \\
\hline $\mathrm{P} 29$ & Dropped out & FBP & Epilepsy \\
\hline $\mathrm{P} 30$ & Dropped out & FUP & None \\
\hline P31 & $\begin{array}{c}\text { Mainstream } \\
\text { School }\end{array}$ & FBP & $\begin{array}{c}\text { Mobility } \\
\text { Issues }\end{array}$ \\
\hline $\mathrm{P} 32$ & No School & FUP & Mobility \\
\hline
\end{tabular}

\begin{tabular}{|c|c|c|c|}
\hline & & & Issues \\
\hline P33 & Dropped out & FBP & CB \\
\hline P34 & No School & FUP & $\begin{array}{c}\text { Mobility } \\
\text { Issues }\end{array}$ \\
\hline
\end{tabular}

Key: FBP - financially better off

FUP - financially under-privileged

$\mathrm{CB}$ - challenging behavior

No school - attended school for less than 6 months

The average age of all the children who were currently in school was 11.3 years. A little more than half of all the children had started school before age 5. Only 2 children had never undergone any sort of educational intervention. More boys belonged to the no school and currently school going categories. Slightly more than half of those from financially better placed backgrounds (FBP) were currently attending school regularly. Most children from the no school category had mobility issues. Most children who had dropped out of school also presented with co-morbidities. However, only half of those who were currently going to school had comorbid issues.

Thematic analysis revealed 5 major themes.

\subsection{Education is necessary}

This theme is related to the perceptions and beliefs that parents held about education of their CWIDD. The sub themes and their relationships have been shown in Figure 1.

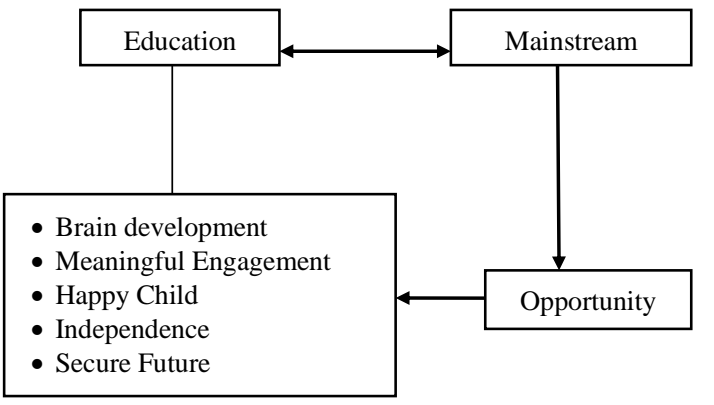

Figure 1. Theme 1 - education is necessary

Parents almost unanimously opined that education helped in their child's brain development and perceived it as an access to their secure future. A little over half of those currently going to school, had returned to school after an average of 5 years at home.

Participants believed that education involved gaining knowledge or critical awareness about the world, and in turn, gaining independence.

'Education is for the self-sufficiency, to spend his time properly. To gain knowledge through learning not for his present; I would say his future.' P2 
'It would have been nice if he had education. He would have been independent. But he doesn't have it.' $\mathrm{P} 8$

They also observed that education was a means of meaningful engagement and that their child liked to learn.

'For her too, something to write, something to read... she wants to go to school. These things come to her mind.' $P 4$

'Due to sitting idle at home, she has become like this. If she had been able to go to a school, she would have been better.' $P 7$

'Education has brought discipline and calmness. Before, he would be irritated all the time.' P16

They believed that school provided an opportunity for their child to have social interactions.

'The regular classroom: that is where I can get socializing.' $P 2$

'She has become alone at home. My other 2 children are good, happy with friends.' $P 9$

All parents felt that by being amongst nondisabled peers, their child could learn better.

'Only in a regular school she can learn anything.' $P 10$

'But really, when we put her in a normal school, she was normal.' P7

For this reason, parents preferred a mainstream school for their child. More than three fourths of all children who ever went to a school attended a mainstream school first. More than one-third of those who had ever gone to a mainstream school had never attended a special school.

\subsection{Mainstream schools don't care}

This theme describes the experiences that parents had while dealing with mainstream schools. Figure 2 depicts the various sub themes under this theme.

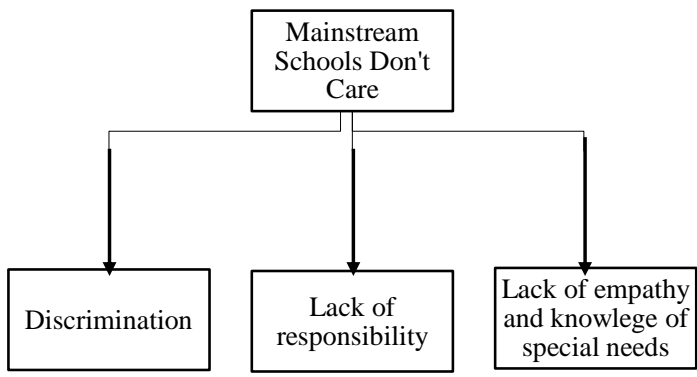

Figure 2. Theme 2 - mainstream schools don't care

Despite their belief in education, parents expressed very low confidence in the schooling system.

Although the average age of starting school was 5.15 years, more than half had also remained out of school for a minimum of 5 years. Those in the no school category had started school at 6.14 years and stayed at home for an average of 7.7 years whereas those currently going to school had started at age 5.3 years and stayed at home for 2.9 years. Children going to a special school tended to spend a little more time at home than those attending mainstream schools -4 years. Three quarters of the teenagers in the sample, (balanced between genders), had dropped out of school.

Most parents wanted to give their CWIDD the same opportunities as their non-disabled peers would get. But at least half of the participants reported discrimination. Children were often denied admission in or asked to pull out their child from a mainstream school because of the child's disability. This was truer for private schools than for government schools. None of the parents sending their child currently to a mainstream school had had this experience but almost all those whose children were either currently going to a special school or had dropped out, had this experience.

"I told the teacher, it's ok if he doesn't write. I just want him to go to school with the other kids. She said, "You'll worry, later on, why the child is not learning despite paying so much money. So, see some other school meant for these kids". P33

'But that teacher said, the others will also become mad. Don't send her. We were pained that from our daughter, they're so disturbed and so many are getting spoilt. So we keep her at home.' P9

Schools and teachers also let other children and parents display acts of discrimination.

'Some children would want to run far away from her. Their parents also might have been saying don't go near her. You'll get her infection.' P4

'I begged the teacher 2-3 times to keep my child in school. We didn't know about any separate school. Even if our child was not learning, we wanted them to let our child at least be with the other kids. She could listen. So she would have learnt to talk. But they said, no because other parents weren't ok with it.' P7

And yet, not a single participant had lodged a formal complaint about the discrimination. In fact, they believed that they deserved this sort of treatment. During the interview, not a single participant showed awareness of the rights of their CWIDD.

'Teacher told, sorry, we can't keep your child. I accepted. Why because, my fault is there. My daughter's fault is there.' P10

Despite their belief in the benefits of mainstream education, parents had very little trust in mainstream schools and the teachers there. Parents expressed deep concern that schools did not provide basic care for their child. Almost two thirds of those, whose children presented with co-morbidities, reported that the school had proved to be a great health risk for their child.

'The child would often come home bruised. Her legs are weak. She would have been hurt badly. 
When we asked the teacher, she said, "Children play and push. That's not my responsibility.' $P 5$

'If I put her in a school, I'm scared that nobody will care for her there. If she falls down again, I'll have to spend again on her health. Health is more important than education, isn 't it?' P20

All participants believed that teachers were unwilling to take responsibility for their disabled child and unreasonably expected parents to fill in.

'Nobody takes the responsibility. Even the class teacher won't take that responsibility. Sometimes, he has even been forced to stay at home for a period of 8 to 15 days. He was forced to; by the teachers. Even the job of explaining is handed over to me". Pl

"I had shadowed my son for 6 years". P2

'What they tell, you know? When we go for admission - you have to be with him. You have to come along. Then, I can teach him at home only, no?' P13

They often found their child being ignored/ neglected by the teacher.

'He's very good at singing. But unfortunately, it's been 3 years now; nobody has noticed that he's so good at singing. Nobody has noticed. No music teacher has noticed that there's an excellent voice he has. He is not taken in the school programs.' PI

'I went for 10 days to check why she cried to go to school every day. She would get up and sit in a corner, all alone. They wouldn't care if she's not eaten. They wouldn't wipe her drool. They wouldn't pay attention to her.' $P 9$

Some parents believed that at home, their daughter was safe from sexual exploitation. Although only a few parents explicitly mentioned this fact, perhaps due to cultural inhibitions, almost half of the boys were found to have never gone to a special school, suggesting that having opportunities for socializing was high on the list for parents of boys but not for parents of girls.

"Future of the child must be good. If anything happens (at school), it'll cause problems for us isn't it - when she grows older?'P28

Parents also believed that mainstream schools and its teachers lacked empathy and understanding of special needs. Teachers often complained instead of helping the parents and could not make the child learn.

'The teacher would call me every day to school to complain about my child.' P8

"'He doesn't study, only disturbs", the teacher used to say.' P3

'Both my children went to the same school. So I would send them together. But my son would walk slowly because of weak legs. My daughter would get late and be punished. She would come back crying every day and hated taking him to school.' P8

'8 schools I have changed as of now. I don't think he has 8 years of learning. One particular year, I took him to 2 schools each day. He was given only an hour of schooling in each.' $P 2$

Thus, although all but 4 children from the sample had attended a mainstream school, only 5 were currently going to a mainstream school.

\subsection{Special schools understand and help}

Parents were comparatively happier with their experiences at special schools. A little more than half of the children who had ever been to a school had attended a special school. Parents almost always chose these schools after facing rejection at a mainstream school. This theme is depicted pictorially in Figure 3.

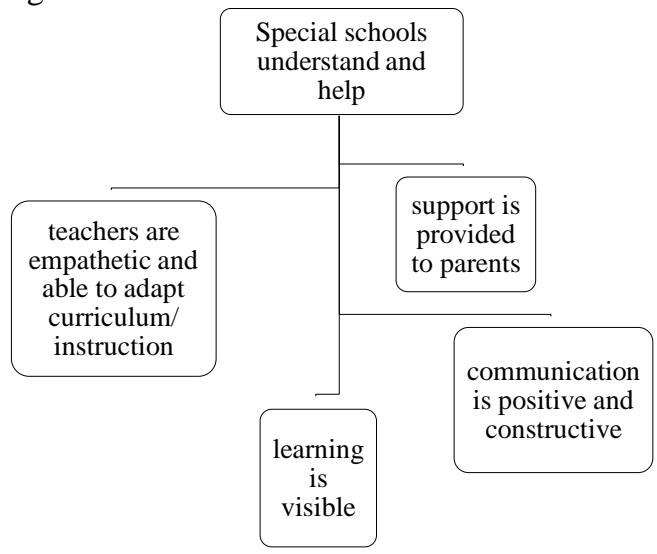

Figure 3. Theme 3 - special schools understand and help

Teachers here were perceived as empathetic and able to adapt their curriculum and instruction to suit the needs of their child.

'In the previous school, he would cry every day to go to school. But here, the teacher looks after him. He likes the teacher a lot. He says he wants to go to her house.' P15 P3

'They love him here. He doesn't feel "degraded".

'My neighbors told me the teacher (at the special school) makes them do exercises to strengthen the legs also.' P30

Participants were able to notice that their child had begun to learn in these schools.

'Now, he has started following instructions. He loves participating in activities.' P15

'My child has become a leader and helps other children follow the teacher's instructions. 'P10

'He wouldn't wear new clothes/shoes before. Now, he wears them.'P3

Special schools provided counseling to parents to enable them to support their child.

'They say, "You are not alone”. "A special child makes a family special"'. P3

Parents also reported that communication with the teacher in special schools was more positive and involved constructive feedback, not complaints. 
'Teacher says, "Send her to school. If she stays at home, she'll only be used to you and she'll trouble you. Here, she'll be with other kids." ' P5

'Every day they would send a diary note to inform me about how much he finished and what he needs to complete at home.' P8

These few positive experiences however were not enough to keep children at special schools. More than half of the children who had ever gone to a special school were currently out of school.

\subsection{We left school because it was unsupportive}

More than half of the parents had changed at least 2 schools. Parents who were currently sending their child to a school had changed at least 3 schools on average. About a quarter (Most from the no school category), had dropped out after just 1 school.

Barriers to school going behavior were analyzed by coding the reasons for leaving the last school. Thematic map of this theme is depicted in Figure 4.

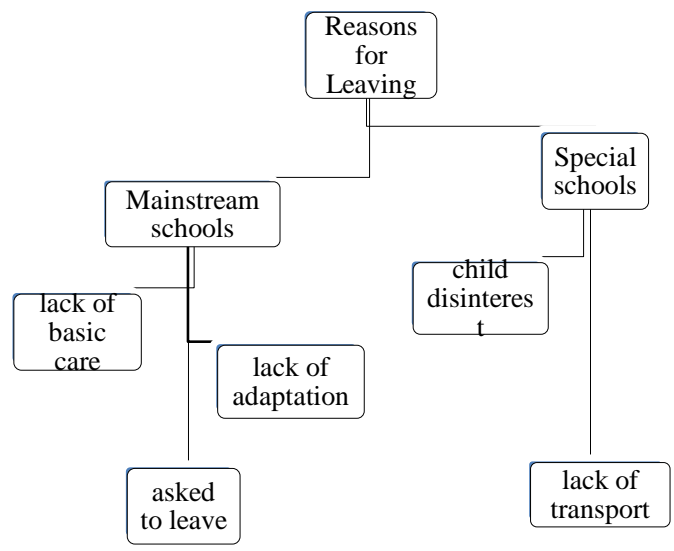

Figure 4. Theme 4 - we left school because it was unsupportive

The most common reason cited for leaving a mainstream school was lack of basic care. This theme cut across the 3 schooling categories, economic status and presence of comorbidities.

'That school didn't bother about my kid. They bothered only about the good ones.' P31

'The teachers, they were very busy. They had no time to take out and you know be with the special kids for what they required to do. Lot of neglect was happening from the teacher's side.' $P 1$

The second most common reason was being asked to pull out the child. More than half of the parents who had ever sent their child to a school reported being asked to pull their child out.

Lack of empathy and reasonable accommodations were cited as other major reasons.

'What they did is, whenever we went there, they didn't care for her. She would be left alone. The doctor wouldn't be there. Once or twice, we fought with them, because she gets epilepsy attacks. Then, we took her out. After that, we've been keeping her at home.' $P 4$

Many a times parents pulled their child out from special schools when they saw that going to school was causing psychological damage to them. They acknowledged that this could be a result of bad experiences at a previous school and not necessarily at the current school. This theme was most common among teenagers who had dropped out of school. No parent stated poverty as a reason for their child being out of school.

'He would run away at the sight of the school van and wouldn't come home for long periods after that.' P8.

'Some teacher had hit her. So she became very scared of school. Out of that fear, she would get a fever and wouldn't eat anything for 2 days. So we thought why give her trouble by sending her to school.' $P 9$

Lack of transport was equally responsible for keeping children out of schools.

'It is a big problem to transport him. It would be nice if we had transport for these children - for study.' P25

'I paid a lot for transport when I had to take her to physiotherapy sessions. I would not buy fruits that time. Now, I want to spend on fruits instead of transport for school.' P20

The following excerpt gives us a glimpse of what mobility means to parents and why transport was a big reason for staying out of school.

'She was about four and a half years old. It was February the $9^{\text {th }}$. 8pm. Saturday. We were watching a dance on TV. Suddenly, she put her steps. Suddenly! I was shocked!! My daughter was walking! From night 8pm, up to $11 \mathrm{pm}$, she walked. Big crowd was there, seeing her. Everyone was clapping. The flooring at that time was uneven. Even then she walked. That's the miracle for me. It is a miracle for me. 4.5 years, I was just... keep your hands here (right hip) and see. It was swelled upto here (shows size of swelling) because I used to carry her everywhere. No transport. Now, there is no swelling, no? It was a miracle for me. I can say that much.'P10

\subsection{We want a learning environment}

This theme explores the expectations that parents have, from a schooling environment, for their child and is shown in Figure 5. 


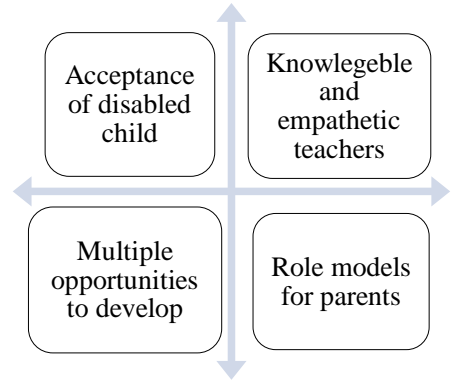

Figure 5. Theme 5 - we want a learning environment

Firstly, parents wanted an environment where their child was accepted and provided basic care.

'First and foremost I ensure there is an acceptance for him in that environment.' $P 2$

'If you're interested, you can take her and teach her. But you should care like how we do at home $(P 21)$

Secondly, participants appreciated if teachers were empathetic.

'She (the teacher) comes home if the child hasn't gone to school to ask if he's fine.' P24

'He sometimes hits other children in school. Their parents complain to the teacher. But the teacher covers it and teaches the students to complain to her first instead of, to their parents. The other parents come to school and scold the child but the teacher intervenes and asks them to resolve it with her first.' P31

They wanted the teacher to recognize their child's unique learning needs and make suitable accommodations for them to ensure their learning happens. This also meant that the curriculum and instruction had to be adapted to meet the child's unique learning goals.

'He goes to grade 5 classroom but does academics of grade 3. When he misbehaves, they take him to the cozy corner where they have toys so that he can calm down. They also make him sit on a gym ball because he's hyperactive and that gives him some movement.' $P 2$

'Now, he does homework on his own. She tells him what to do and how, at school.' P31

'He used to write the exams also in the resource lab. Not in the, you know, regular class where the other kids are writing. Because he needs to be prompted, he needs to be reminded, that this is exam, you need to write. He was quite ok with that.' P1

Parents expressed joy at seeing their child participating in extra-curricular activities, knowing their children had multiple opportunities to develop just like other kids. More parents who had sent their children to private schools longed for this.

'He likes the school because there's horse riding and swimming. So, at 3.30pm, even if I say no, he says, "mama no class" and runs to the stables.' P1

'So, I look into a school only on the aspect of socializing, mingling and having him one among them in all these: lunch time, break time, all the activity based. Any of the art and craft activity anything for that matter, they are having him in the classroom'. $P 2$

'They have sports, dance, arts etc. He even danced for Independence Day.' P3

Most parents confessed that they didn't know how to teach their child sometimes and looked up to teachers to be role models for them.

'Whatever I know, I teach her. I observe the teachers and teach her.' P20

'We will ask the teacher how to teach her and give her practice at home.' P5

\section{Discussion and Conclusion}

The results of this study highlight that all parents, regardless of their own education and financial status, are acutely aware of the benefits of peer learning for their CWIDD, specifically alongside non-disabled peers. This is interesting, especially because poverty has been a big barrier to school going behavior among non-disabled children [2]. The desire for inclusive education has been expressed by parents in the Western world too [11, 12]. A previous Indian study had also found that children had been sent to mainstream schools before being shifted to special schools, which parents considered as safe havens [7]. However, caution needs to be employed while interpreting the low opting rates of special schools in the current study. Cultural beliefs, low awareness of special schools, better visibility of mainstream schools and the psychological need to feel "normal", must be ruled out before concluding that most parents do not prefer them for the evidenced benefits of inclusive settings.

Gross negligence and discrimination by staff in mainstream schools was reported by many parents, irrespective of socio-economic backgrounds. Most parents had been asked to pull out their child. And all parents had experienced denial of admission due to the child's disability. Other Indian studies have also found similar results [7]. Thus, it could be coincidental that none of the parents, who were currently sending their children to school, had reported being asked to pull their child out.

More private schools than government schools had asked children with IDD to leave. Although the obligation placed on government schools (to ensure that every child in the neighborhood, regardless of disability, is attending school) maybe restricting this behavior, it is not enough to explain why so many children had dropped out and never returned. Yet, it reveals that access to schooling maybe better for CWIDD from financially under-privileged backgrounds than for those from financially betterplaced backgrounds because the former prefer government schools and the later prefer private ones. 
This is shocking, given our common belief that economic power increases opportunities.

Yet, no parent had raised their voice against this discrimination. They also did not display awareness of their child's rights. This could mean that they didn't recognize acts of discrimination for what they were and that's why, blamed themselves or the disability of their child. An Irish survey [11] that found similar results suggests that even access to this information may be difficult to obtain for parents.

Given the high possibility of widespread discrimination, lack of responsibility, empathy and care, it is possible that even school managements are unaware of the child's rights and their own accountabilities. Majority of teachers have been found to possess low levels of knowledge on the needs of children with disabilities [13]. However, more studies are needed to explore how much and how well school managements and policy makers understand the needs of children with disabilities.

A study by Kalita and Sarmah [4] had also observed that drop-out rates increase steeply with age, in Indian CWIDD, especially after age 8. This could explain why the average age of children currently in school, in the present study, is pre adolescent. It is possible that most teenagers had dropped out because providing support for comorbid complexities associated with teenage and IDD, in addition to designing an appropriate curriculum for this age group, were probably out of scope for schools.

In the current study, girls and boys were equally cared for and given/denied opportunities equally. Parents were as anxious to educate their daughters as they were to educate their sons. Although this study also noted that more girls were out of school than boys, no evidence of gender specific discrimination by parents was found. This is a refreshingly surprising result, considering that among non disabled children, more girls are out of school mainly due to gender discrimination [2]. Previous studies on out of school disabled children also support this result [1]. Considering that parents of girls with IDD gave menstrual hygiene and sexual safety more prominence in this study, it is possible that apart from the complexities of teenage, IDD and bad learning histories, which are common for both boys and girls with IDD, inability of schools to garner trust of parents with regards to menstrual hygiene and sexual safety, kept girls with IDD more frequently out of schools.

Indian studies have documented a good number of parents as being unsatisfied with the teaching and learning aids being used by the teachers. When resource rooms were assessed, teachers were found not to be using learning materials that would meet the needs of students [14].

In one impact study [5], teacher participants had expressed concern over the fact that having CWSN alongside "normal children" would severely affect the "normal" children's education. This too, is a common sentiment among teachers, who have been found to be the least supportive of inclusion, especially of students with moderate and severe disabilities [15]. This study also found that parents of children without disabilities had low acceptance of children with disabilities.

However, attempts to train Indian teachers in modern pedagogy, in order to empower and enable them to support children with special needs in mainstream schools, has not yielded impressive results. In a recent study conducted to evaluate the effectiveness of one such teacher training program, participants reported that the program was of little use to them [16]. Another study [13] recommended that instructional methodologies must be adapted to the Indian context.

Much research has been done internationally on what constitutes good education for children with disabilities and it is imperative that these core ideas are incorporated in Indian training programs too. Ferguson [17] writes that many European countries such as Norway, Greece, Portugal, Spain, Estonia, Lithuania, Luxembourg and Italy are now supporting $80-90 \%$ of their disabled children in mainstream schools. A cross-continental study on training preservice teachers concluded that those who directly and regularly interacted with students with disabilities, understood various disabling conditions and were aware of policies and legislation supporting inclusion, were more confident about teaching students with disabilities [18] Another study [19] found that organizing school activities and implementing them in such a manner as to enable the participation of disabled students in both physical and social environments is the key to inclusive education.

It was surprising to find that lack of transport was causing many parents to pull their child out of school, especially in this age and day, when transport has become more accessible than ever and after multiple studies have repeatedly stressed on the need for school transport for children with special needs. Although many parents had a free pass for the government run buses, they found that bus stops were quite far and carrying the child till there or up and down the bus, was quite difficult and put their own health at risk. Since, most of them belonged to financially under-privileged sections of the society, they couldn't afford private transport.

It is also possible that odds are stacked against some children and consequently their parents, more than against others, with regards to access to school and good quality education. The following maybe contributing factors: presence of comorbidities; reduced societal participation of parent; type of organization - private or government and lack of 
exposure to training. However, more studies are required to validate these factors statistically.

All of these results must be considered with some caveats in mind. Firstly, income levels were just estimates based on observation of size of the house, number of resident family members, number of private services opted for, approximate amount spent on services and mention of financial difficulties. Secondly, the cities where the participants resided are two of the most developed cities of India and have the lowest school drop-out rates. They are also culturally quite different from the rest of the country. In addition, parents gave only estimates of ages at which their child joined or left a school, and the number of schools which had denied their child admission on the grounds of disability.

Despite these limitations, it is evident that parents want their CWIDD to be educated and prefer mainstream schools to special schools. Lack of supportive and conducive care cum-learning environments at schools, for both CWIDD and their parents, are keeping Indian CWIDD out of schools. Most vulnerable are teenage girls who lose interest in education due to unsupportive teacher characteristics as well as negative, discouraging, past learning experiences but also face the risk of sexual exploitation.

To end the appalling, widespread discrimination of CWIDD, schools and teachers need to be held accountable for upholding the educational rights of CWIDD, by way of training and sensitizing all stake holders. The training/sensitization program must be centered on increasing the interaction between the non-disabled and the families of CWIDD. This could help reduce societal pressure on schools to remain non-inclusive. Schools as well as individual teachers must be given substantial incentives, to take in a child with disabilities and given strict punishments, for denying admission or displaying discriminatory behaviors. However, care must be taken that the incentive is not purely financial. A framework such as the response to intervention [20] is necessary to enable schools to decide and plan for, based on evidence, the type and level of intervention required for a CWIDD. If a child requires intensive support in a special environment like a special school, the special school must have a plan to transition the child into a mainstream school and mainstream schools must be held accountable for following through with the transition when the time arrives. In the context of "Kaizan" or "continuous improvement", when evidenced practices are adopted by schools and decisions are based on scientifically collected data, inclusion can be achieved [17].

Information about child rights and pathways to seek help/justice must be made widely available. Nationwide campaigns such as the one underway for educating the girl child must be conducted. Displaying educational rights of a child in an easy read format in every classroom and the gates of a school must be made mandatory so that children's school going behavior is self-reinforced. These posters must also include contact details of a go-to person that parents can approach to seek help in case of violation of rules.

Policy makers must work at increasing the visibility of CWIDD. When the visibility of CWIDD increases, the general population will have more opportunities to interact with them and thus, be confident and responsible for including them in the society.

In the words of Diane Ferguson [17], "The good news is that we already know most of what we need to know to transform schools into inclusive systems. What remains is to do the task".

\section{Acknowledgement}

The author wishes to acknowledge the significant contribution of her dissertation supervisor Michelle McCarthy, as well as Mr Ganesh and his colleague Mrs. Sara from the NIEPID, Hyderabad, India. Special thanks to all the mediators and participants.

\section{References}

[1] Verma, D., Dash, P., Bhaskar, S., Pal, R. P., Jain, K., Srivastava, R. P., et al. (2017). Disabled_persons_in_India _2016. Retrieved from http://mospi.nic.in/sites/default/ files/publication_reports/Disabled_persons_in_India_2016. pdf. (Access date: 3 December, 2019).

[2] Social and Rural Research institute, I. I. (2014). National-Survey-Estimation-School-Children-DraftReport. Retrieved from https://mhrd.gov.in/sites/upload _files/mhrd/files/upload_document/National-SurveyEstimation-School-Children-Draft-Report.pdf. (Access date: 1 March, 2020).

[3] Peshawaria, R., Menon, D. K., Ganguly, R., Roy, S., Pillay, R. P. R. S., and Gupta, A. (1995). Understanding Indian families having persons with mental retardation. Secunderabad: National Institute for the Mentally Handicapped.

[4] Kalita, J., and Sarmah, P. (2012). Some statistical characteristics of special education for children with disabilities in North-East India. Journal of Research in Special Educational Needs, 12(2), 82-95.

[5] Srivastava, A. B., and Bala, N. (2010). abstracts-ofresearch-studies-in-elementary-education. Retrieved from https://www.educationforallinindia.com/abstracts-ofresearch-studies-in-elementary-education.PDF. (Access date: 12 February, 2020).

[6] O'Keefe, P. B. (2007). People with disabilities in India: From commitments to outcomes (No. 41585, pp. 1-186). The World Bank. 
[7] John, A., Bailey, L. E., and Jones, J. L. (2017). Culture and context: Exploring attributions and caregiving approaches of parents of children with an intellectual disability in urban india. Child and Family Social Work, 22(2), 670-679. doi:10.1111/cfs.12282.

[8] Ansari, N.J.R., Dhongade, R. K., Lad, P. S., Borade, A., S.,Y.G., Yadav, V., . . Kulkarni, R. (2016). Study of parental perceptions on health and social needs of children with neuro-developmental disability and its impact on the family. Journal of Clinical and Diagnostic Research, 10(12), 16-20. doi:10.7860/JCDR/2016/22538.9039.

[9] Braun, V. (2005). In search of (better) sexual pleasure: Female genital 'cosmetic'surgery. Sexualities, 8(4), 407424.

[10] Braun, Virginia and Clarke, Victoria (2006) Using thematic analysis in psychology, Qualitative Research in Psychology, 3:2, 77-101.

[11] Watson, S. F. (2009). Barriers to inclusive education in Ireland: The case for pupils with a diagnosis of intellectual and/or pervasive developmental disabilities. British journal of learning disabilities, 37(4), 277-284.

[12] Gasteiger-Klicpera, B., Klicpera, C., Gebhardt, M., and Schwab, S. (2013). Attitudes and experiences of parents regarding inclusive and special school education for children with learning and intellectual disabilities. International Journal of Inclusive Education, 17(7), 663-681.

[13] Julka, A. (2005). Educational provisions and practices for learners with disabilities in india. Paper presented at the Inclusive and Supportive Education Congress (ISEC) 1st4th August.

[14] Sarva Shikshana Abhiyan (2010): Progress Overview Of Research. New Delhi: Education Council of India (2010).

[15] Sin, K. F., C. Forlin, M. L. Au, F. C. Ho, M. Lui, and Z. Yan. 2012. Study on Equal Learning Opportunities for Students with Disabilities under the Integrated Education System. Hong Kong: Equal Opportunities Commission and Centre for Special Educational Needs and Inclusive Education, HKIEd.

[16] Yadav, S. K. (2012). SSA\%20INSET. Retrieved from http://www.ncert.nic.in/departments/nie/dtee/publication/p rint_material/SSA\%20INSET.pdf. (Access date: 14 April, 2019).

[17] Ferguson, D. L. (2008). International trends in inclusive education: The continuing challenge to teach each one and everyone. European Journal of special needs education, 23(2), 109-120.

[18] Sharma, Umesh, Chris Forlin, and Tim Loreman. "Impact of training on pre-service teachers' attitudes and concerns about inclusive education and sentiments about persons with disabilities." Disability and Society 23.7 (2008): 773-785.
[19] Hemmingson, H., and Borell, L. (2002). Environmental barriers in mainstream schools. Child: care, health and development, 28(1), 57-63.

[20] Fuchs, D., and Fuchs, L. S. (2006). Introduction to response to intervention: What, why, and how valid is it?. Reading research quarterly, 41(1), 93-99. 